\title{
A COMPARISON OF THREE RUBBER DAM SYSTEMS IN VIVO - A PRELIMINARY STUDY
}

\author{
Martin Kapitán, Tereza Suchánková Kleplová, Jakub Suchánek
}

Charles University in Prague, Faculty of Medicine in Hradec Králové and University Hospital Hradec Králové, Czech Republic, Department of Dentistry

Summary: The aim of this study was to compare the isolation systems OptraDam ${ }^{\circledR}$ Plus and OptiDam ${ }^{\mathrm{TM}}$ with the conventional rubber dam in terms of objective and subjective parameters. The isolation systems were applied during the dental treatment of the patients. The time of preparation, placement, presence and removal were measured and the quality of isolation was evaluated. The median time of rubber dam placement was $76 \mathrm{~s}(\mathrm{Q} 1=62 \mathrm{~s} ; \mathrm{Q} 3=111.25 \mathrm{~s})$. The application time of OptraDam ${ }^{\circledR}$ Plus was significantly longer compared to the other systems $(\mathrm{P}<0.001)$. The median volume of fluid remaining in the isolated space after 5 minutes was $4.9 \mathrm{~mL}(\mathrm{Q} 1=4 \mathrm{~mL} ; \mathrm{Q} 3=5 \mathrm{~mL})$. The differences between the systems with regards to isolation quality were not statistically significant. The majority of the patients reported a higher level of comfort during the treatment with a rubber dam than without it. The attitude of patients was not affected by any of the observed factors. The ranking of the isolation systems according to the subjective evaluation by the patients was (from best to worst) OptiDam ${ }^{\mathrm{TM}}$, conventional rubber dam, OptraDam ${ }^{\circledR}$ plus. The results presented in this study could guide clinicians for choosing the most appropriate isolation system.

Keywords: Dental equipment; Isolation quality; Operation field; Rubber dam

\section{Introduction}

The rubber dam (RD) is a device for isolation of the working field during different dental maneuvers including restorative and endodontic procedures (1). It improves the outcome of the root canal treatment (2). The RD was introduced to dentistry by Dr. Barnum in $1864(3,4)$. The method of RD placement has almost stayed the same since then. The undergraduate dental students are taught the work with $\mathrm{RD}$ as a standard of care, however many of them do not continue its use after graduation (5). The RD is not used often by the dental practitioners in the Czech Republic $(6,7)$ nor in many other countries $(8,9)$, even though it is recommended by many dental authorities such as European Society of Endodontology (10) and American Association of Endodontists (11). The assumption that RD application is time-consuming as well as concerns about patients' attitude are the main reasons for the negative opinion of dental practitioners towards RD application $(8,12-16)$. The arguments against RD use are still widespread, even though these views are discordant with modern day literature (17-21). As the RD technique is assumed difficult and time-consuming by many dentists, new isolation systems have been developed in the last few years. The producers of these systems declare work with their products to be easier and faster.
This work is a continuation of a previous study (22), which compared the properties of three isolation systems with regards to time consumption and isolation quality of the working field. OptiDam ${ }^{\mathrm{TM}}$ system demonstrated better results than conventional $\mathrm{RD}$, yet both systems were better than OptraDam ${ }^{\circledR}$ Plus system. The application of the RD in a model fitted in a dental simulator was the main limitation of that study, which may not reflect the properties of the RD when applied in the clinical situation (22).

The aim of this study was to compare the properties of three isolation systems (OptiDam ${ }^{\mathrm{TM}}$, OptraDam ${ }^{\circledR}$ Plus and the conventional RD) in clinical testing. The hypotheses of the present study were that (a) the application of the isolation systems OptiDam ${ }^{\mathrm{TM}}$ and OptraDam ${ }^{\circledR}$ Plus is faster than conventional $\mathrm{RD}$, without affecting the efficiency of isolation; (b) the attitude of the patients towards RD is positive; (c) all the tested isolation systems are the same comfortable for the patients.

\section{Material and methods}

The material and methods were based on our previous study $(6,22)$ with few changes in the application techniques. The RD systems were as follows:

- A conventional RD consisting of latex membranes (Nic tone Dental Dam, thin, mint, MDC dental, Zapopan, 
Mexico) and the basic set of instruments Fit Kofferdam ${ }^{\circledR}$ Starter Kit I (Hager \& Werken, Duisburg, Germany).

- OptraDam ${ }^{\circledR}$ Plus (Ivoclar Vivadent, Schaan, Lichtenstein).

- OptiDam ${ }^{\mathrm{TM}}$ (Kerr Hawe SA, Bioggio, Switzerland). All systems were placed using an "all at once" technique with the following steps:

- The positions of the holes for isolated teeth were marked on the membrane according to the template (conventional RD only).

- The membrane was perforated with a punch adjusted to create holes of suitable sizes (conventional RD and OptraDam ${ }^{\circledR}$ Plus).

- The membrane was stretched onto the plastic frame and the holes were cut with scissors (OptiDam ${ }^{\mathrm{TM}}$ only).

- A winged clamp was threaded into the hole for the anchor tooth.

- The membrane was attached to a frame (conventional RD).

- The clamp, frame and membrane were placed into the mouth of the patient all at once using application forceps.

- Margins of the hole for the anchor tooth were pulled under the clamp wings and the other holes in the membrane were adapted to the cervices of the corresponding teeth using dental floss.

- Finally the membrane was stretched onto the frame (conventional RD only).

Figures $1 \mathrm{a}-\mathrm{c}$ and $1 \mathrm{~d}-\mathrm{f}$ show the membranes prepared for application and after placement in the patient's mouth, respectively.

The study was performed by three dentist's working at the Department of restorative dentistry and endodontology, who routinely use RD. Patients from the Department of Dentistry, Charles University, Faculty of Medicine in Hradec Králové, and the University Hospital Hradec Králové, scheduled for restorative or endodontic treatment of premolars or molars were included in this study. Each patient was informed about the study design and procedures, and signed an informed consent upon agreement. Patients drew the isolation system, which was to be used for their first treatment. If they came for a second treatment, they only drew from the remaining two systems. In the case of a third treatment, the last unused system was used without drawing. Each isolation system was used thirty times. A questionnaire (fig. 2), was prepared for recording data, patients' information and answers, as reported in our previous study (18).

The preparation time of the RD system was measured. After application of local anaesthesia, the isolation system was placed as described previously. The number of isolated teeth varied according to the demands of the situation. The number of isolated and treated teeth as well as the type of treatment was recorded. The RD application time and the duration of its use were measured. Before commencing the treatment procedures, an evaluation of the isolation quality was performed. The isolated space was rinsed with water and dried with air. A volume of $5 \mathrm{ml}$ of $5 \%$ glucose solution was poured into the isolated space. The time measurement was started at this moment. Patients were asked to let us know by raising their hands about whether or not they could detect a sweet taste in their mouths. If so, the time of this event was recorded. The fluid remaining in the isolated space was aspirated into a $5 \mathrm{ml}$ syringe after five minutes and its volume was read. In case of complete leakage, the time was recorded. After the evaluation of isolation quality, the planned treatment was carried out. Finally, the time of RD removal was measured.

Every patient recorded his/her experience towards the $\mathrm{RD}$ system(s) in the questionnaire. The questionnaires were filled out in the waiting room without the presence of the doctor. The patients had the right to abandon the study at any time. Ethical approval was obtained from the Ethics Com-

\begin{tabular}{|c|c|c|}
\hline Study protocol & No. & $\ldots$ \\
\hline $\begin{array}{l}\text { Isolation system (Conventional }{ }^{1} \text { x } \\
\text { OptraDam }^{\circledR} \text { Plus }^{2} \text { x OptiDam }{ }^{\text {TM }}{ }^{3} \text { ) }\end{array}$ & & $\ldots$ \\
\hline $\begin{array}{l}\text { Treatment type } \\
\left(\text { root canal treatment }{ }^{1} \mathrm{x} \text { restoration }{ }^{2}\right)\end{array}$ & & $\cdots$ \\
\hline Number of treated teeth & & ... teeth \\
\hline Number of isolated teeth & & ... teeth \\
\hline Treatment of the anchor tooth $\left(\mathrm{yes}^{1} \mathrm{x} \mathrm{no}^{2}\right)$ & & $\cdots$ \\
\hline Preparation time & & $\ldots s$ \\
\hline Placement time & & $\ldots \mathrm{s}$ \\
\hline Sweet taste & & $\ldots \mathrm{s}$ \\
\hline Complete leakage & & $\ldots s$ \\
\hline Remaining volume & & $\ldots \mathrm{mL}$ \\
\hline Removal time & & $\ldots s$ \\
\hline Presence time & & $\ldots \min$ \\
\hline Age & & ... years \\
\hline Gender $\left(\operatorname{man}^{1} \mathrm{x}\right.$ woman $\left.{ }^{2}\right)$ & & $\ldots$ \\
\hline
\end{tabular}

To be filled out by the patients - please circle your answers

- Have you undergone the dental treatment with a rubber dam? YES ${ }^{1}-\mathrm{NO}^{2}$

- How would you describe the comfort level during the treament with a rubber dam compared with the treatment without it?

MORE COMFORTABLE ${ }^{1}$ - THE SAME ${ }^{2}$ LESS COMFORTABLE ${ }^{3}$

- The isolation system used today was BETTER ${ }^{1}$ THE SAME ${ }^{2}-$ WORSE $^{3}$ than the last time.

- The isolation system used today was BETTER ${ }^{1}$ - THE $\mathrm{SAME}^{2}-$ WORSE$^{3}$ than the time before the last time.

Fig. 2: The study protocol with questionnaire. 
mittee of the University Hospital Hradec Králové, reference number 201210 S07P.

The collected data was statistically analysed with the NCSS 9 program using the methods of descriptive statistics,
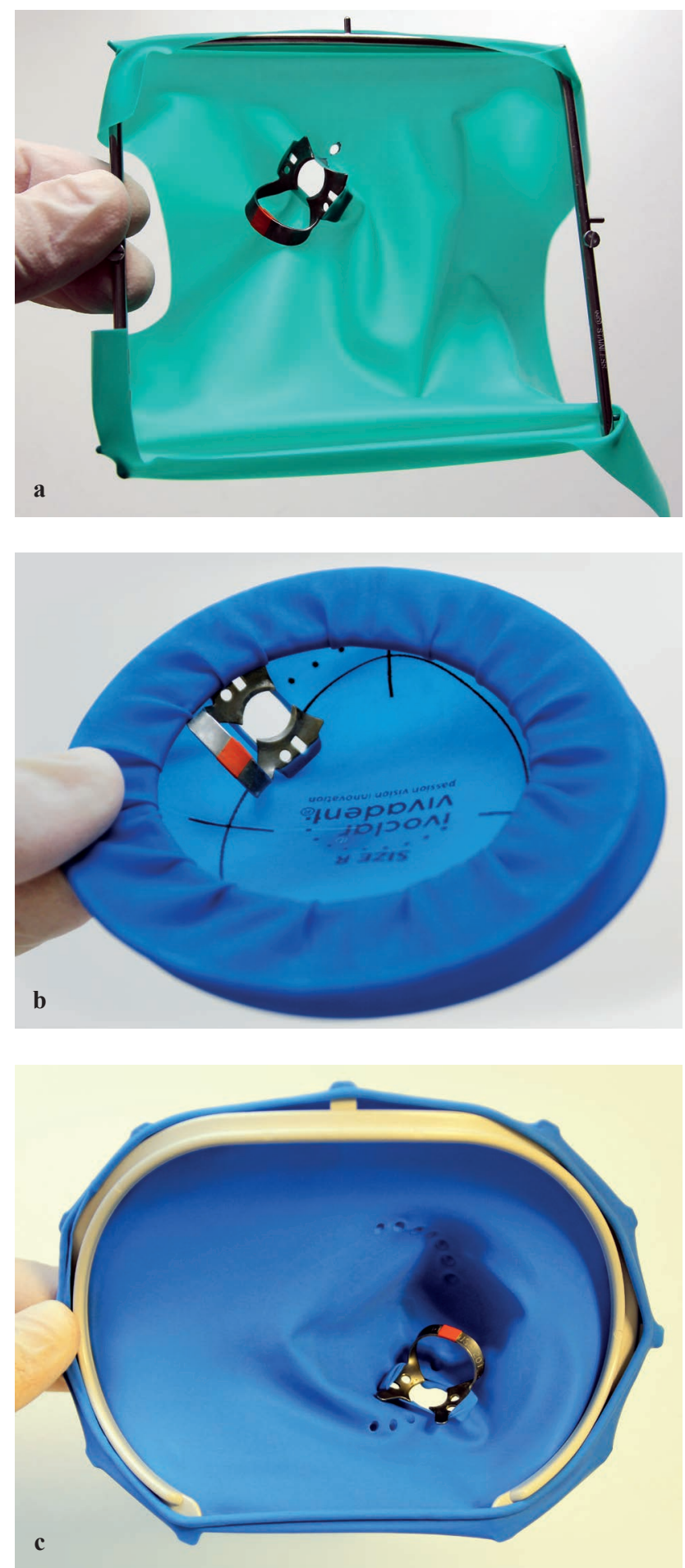

the non-parametric Mann-Whitney test, the Kruskal-Wallis one way analysis with post hoc Dunn's test and the chisquared test or Fisher's test. The level of significance was set at 0.05 .
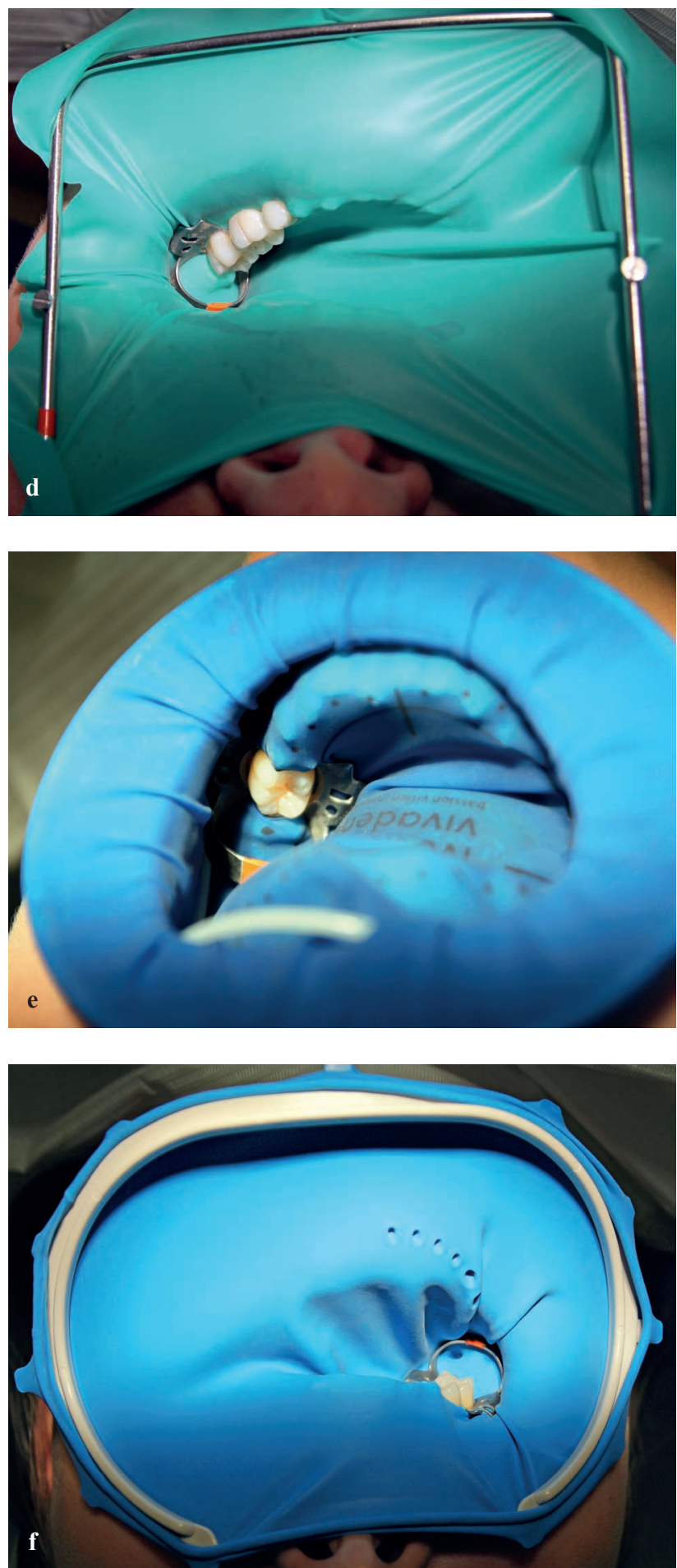

Fig. 1: Conventional rubber dam (a), OptraDam ${ }^{\circledR}$ Plus (b) and OptiDam ${ }^{\mathrm{TM}}$ (c) prepared for the application and placed in the patient's mouth $(\mathrm{d}-\mathrm{f})$. 


\section{Results}

\section{Sample and treatment characteristics}

A total of 62 patients were involved in the study. From those, 41 patients participated once, 14 patients participated twice and 7 patients participated three times. A total of 90 measurements were taken. $46.8 \%$ of the patients were males $(n=29)$ and $53.2 \%$ were females $(n=33)$. The age range was from 16 to 65 years with the average of 36 years. Previous experience with a RD was declared in $81.1 \%$ of cases $(n=73)$.

Root canal treatment was performed in $36.7 \%$ of cases $(\mathrm{n}=33)$; while a restorative procedures were carried out in the remaining cases $(63.3 \%)$. Table 1 summarizes the number of treated and isolated teeth. The number of isolated teeth was higher than the number of treated teeth in $85.6 \%$ of cases $(n=77)$; in the remaining cases the number of the isolated teeth was the same as the number of the treated teeth. The anchor tooth was treated in $35.6 \%$ of cases $(n=$ 32). No statistically significant differences between the RD systems were found in the all above mentioned parameters.

Tab. 1: Number of treated and isolated teeth.

\begin{tabular}{|l|c|c|}
\hline & treated & isolated \\
\hline No. of teeth & $\mathrm{n}(\%)$ & $\mathrm{n}(\%)$ \\
\hline 1 & $64(71.1)$ & $9(10.0)$ \\
\hline 2 & $23(25.6)$ & $10(11.1)$ \\
\hline 3 & $2(2.2)$ & $55(61.1)$ \\
\hline 4 & $1(1.1)$ & $12(13.3)$ \\
\hline 5 & & $4(4.4)$ \\
\hline
\end{tabular}

\section{Objective comparison}

The time of preparation, placement, presence and removal of the RD along with the volumes of remaining fluid for the RD systems, separately and together, are summarized in table 2. The distribution of the data is not normal, thus, the medians and quartiles are given.
Data concerning detection of sweet taste or complete leakage is listed in table 3. Statistical analysis was not possible for the small number of these cases.

The application time in the case of isolation of one or two teeth was significantly shorter than in cases of isolation of three or four teeth $(\mathrm{P}<0.05)$. The number of isolated teeth did not have a statistically significant effect on the preparation time, removal time nor the isolation quality.

The treatment time (time of RD presence) of two teeth was significantly longer than a single tooth $(\mathrm{P}<0.001)$. The treatment time was not affected by the type of treatment nor the treatment of the anchor tooth.

\section{Subjective evaluation}

The treatment with the RD was more comfortable than without in $86.7 \%$ of cases $(n=78) ; 11.1 \%(n=10)$ had the same comfort level; and was less comfortable in $2.2 \%$ of cases $(n=2)$. The level of comfort declared by the patients was not affected by the observed subjective (age, gender, previous experience with the treatment with a RD) nor objective factors (isolation system, time of RD placement, treatment time, number of isolated and treated teeth).

The results of patients' subjective comparison of the RD systems are summarized in table 4 .

\section{Discussion}

The aim of this study was to compare the isolation systems OptraDam ${ }^{\circledR}$ Plus and OptiDam ${ }^{\mathrm{TM}}$ with the conventional RD, and to investigate the attitude of towards the RD. In this study, objective measurement was combined with a questionnaire to provide an accurate assessment of the RD systems used.

In most cases one tooth was treated, while a group of three teeth was isolated. The isolation of a group of teeth was often carried out, because it provided an improved access to the working field and a better overview.

Statistically significant differences in the observed parameters were found during the comparison of the isolation systems. The time of preparation of OptraDam ${ }^{\circledR}$ Plus was

Tab. 2: Measured times and volumes for isolation systems (separately and together).

\begin{tabular}{|l|ccccc|c|}
\hline & Conventional & \multicolumn{1}{|c}{ OptraDam $^{\circledR}$ Plus } & OptiDam & TM & Together \\
\hline Preparation (s) & $42(37.75 ; 47)$ & + & $32.5(25.75 ; 36.25)$ & $\dagger$ & $37.5(34.75 ; 45)$ & $37(33 ; 44.25)$ \\
\hline Placement (s) & $66(57.25 ; 83.25)$ & + & $115(84 ; 135.75)$ & $\ddagger$ & $66.5(54.5 ; 91)$ & $76(62 ; 111.25)$ \\
\hline Removal (s) & $11(9.75 ; 13)$ & + & $15.5(12.75 ; 19.25)$ & $*$ & $13(11 ; 15)$ & $13(11 ; 16)$ \\
\hline & $\mathrm{L}$ & & $*$ & \lrcorner & \\
\hline Presence (min) & $54.5(43 ; 71.25)$ & $*$ & $40.5(29.5 ; 51.75)$ & $45.5(29 ; 60.25)$ & $45(32.75 ; 61)$ \\
\hline Volume (mL) & $4.85(3.8 ; 5)$ & & $4.8(3.75 ; 5)$ & $4.9(4.4 ; 5)$ & $4.9(4 ; 5)$ \\
\hline
\end{tabular}

Median values are given along with $\mathrm{Q} 1$ and $\mathrm{Q} 3$ parentheses.

$* \mathrm{P}<0.05, \quad+\mathrm{P}<0.01, \quad+\mathrm{P}<0.001$ 
Tab. 3: The information about the cases of the detection of sweet taste or complete leakages.

\begin{tabular}{|l|c|c|c|c|}
\hline \multirow{2}{*}{} & \multicolumn{2}{|c|}{ Sweet taste } & \multicolumn{2}{c|}{ Complete leakage } \\
\cline { 2 - 5 } & $\mathrm{n}$ & time $(\mathrm{s})$ & $\mathrm{n}$ & time $(\mathrm{s})$ \\
\hline Conventional & 8 & $15(13.25 ; 116)$ & 1 & $154(154 ; 154)$ \\
\hline OptraDam $^{\circledR}$ Plus & 7 & $80(15 ; 120)$ & 3 & $50(10 ; 240)$ \\
\hline OptiDam $^{\mathrm{TM}}$ & 8 & $25(10 ; 45)$ & 4 & $62(37.5 ; 83.5)$ \\
\hline Total & 23 & $30(13 ; 104)$ & 8 & $62(35 ; 138)$ \\
\hline
\end{tabular}

For the times the median is given along with Q1 and Q3 parentheses.

shorter than the other two systems. This could be explained by the fact that the frame is an integral part of the membrane, which doesn't need to be stretched onto it. However, this parameter is not clinically important, because an extensive part of the preparation can be done before the patient's arrival, thus not prolonging the treatment time.

The time needed for the RD placement was between 1 and 2 minutes. Similar placement time was reported in other studies (17-19). This time is negligible within the whole treatment time, thus the use of the RD doesn't significantly prolong the treatment time. This argument is often presented by the dentists who don't use it $(13,15,16)$. The time of $\mathrm{RD}$ placement is affected by the experience of the operator $(17,18,21)$. The placement time of OptraDam ${ }^{\circledR}$ Plus was significantly longer than the other two tested systems. The placement of RD in patients took a longer time compared to placement in a simulator model. It seems more difficult to place a RD in the real patient than in the simulator. This could be attributed to differences in the teeth shape and position or by the presence of the surrounding tissues, i.e. tongue, lips and cheeks.

A statistically significant difference in the time of RD presence was found between OptraDam ${ }^{\circledR}$ Plus and the conventional RD. This time was considered as a measure of the duration of the treatment. The cause and clinical relevance of this finding are not clear.

The removal of the RD usually lasted between 10 to 15 seconds and didn't cause a significant prolongation of the treatment time. Thus, the statistically significant differences between the systems found in this parameter are not clinically important.

No statistically significant differences in the isolation quality were found in this study. The influence of the number of isolated teeth on the isolation quality was not statistically significant. Both of these findings are in contradiction with the results of our previous study (22). We assume that the current study brings more relevant results, because it is not burdened with the limits of the simulator model. The properties of artificial teeth and gingiva don't accurately match the properties of the real tissues. The overall isolation quality can be assessed as very good. Only $2 \%$ of the fluid leaked from the isolated space into the oral cavity during the 5-min-
Tab. 4: Subjective comparison of rubber dam systems.

\begin{tabular}{|l|c|c|c|c|}
\hline & $>$ & $=$ & $<$ & total \\
\hline $\begin{array}{l}\text { Conventional } \\
\text { vs. OptraDam } \\
\text { Plus }\end{array}$ & $\mathbf{1 9 ( 5 7 . 6 )}$ & $3(9.1)$ & $11(33.3)$ & 33 \\
\hline $\begin{array}{l}\text { Conventional } \\
\text { vs. OptiDam }\end{array}$ & $8(25.8)$ & $9(29)$ & $\mathbf{1 4}(\mathbf{4 5 . 2 )}$ & 31 \\
\hline $\begin{array}{l}\text { OptraDam } \\
\text { vs. Plus }\end{array}$ & $2(18.2)$ & $2(18.2)$ & $\mathbf{7 ~ ( 6 3 . 6 )}$ & 11 \\
\hline
\end{tabular}

The most common answers for each pair are in bold.

ute period. It can be assumed that the volume of leaked fluid is even smaller during the treatment, because the fluid is continually suctioned.

In accordance with our expectation, the time of treatment of two teeth was longer than in the cases of one tooth. Although the treatment of the anchor tooth is complicated by restricted access, the treatment time was not affected in such cases.

The majority of the patients declared a higher level of comfort during the treatment with $\mathrm{RD}$, compared with the treatment without the RD. This is in accordance with other studies (17-19). None of the observed factors (age, gender, previous experience with the treatment with a RD, used isolation system, time of $\mathrm{RD}$ placement, treatment time, number of isolated and treated teeth) showed statistically significant influence on the declared comfort. During the subjective evaluation of the isolation systems, the patients mostly stated, that (i) the conventional RD was better than OptraDam $^{\circledR}$ Plus, (ii) OptiDam ${ }^{\mathrm{TM}}$ was better than the conventional RD and (iii) OptiDam ${ }^{\mathrm{TM}}$ was better than OptraDam ${ }^{\circledR}$ Plus. The differences could be caused by different amount of powder, taste, surface structure or the way of placement of the isolation systems. Despite these differences, the overall acceptance of RD among the respondents was very high.

The comparison of OptraDam ${ }^{\circledR}$ and the conventional $\mathrm{RD}$ based on the information from the patients and dentists showed, that the new isolation system is not better than the conventional RD (23). The same conclusion can be drawn from our results regarding the system OptraDam ${ }^{\circledR}$ Plus. Contrarily, the OptiDam ${ }^{\mathrm{TM}}$ system was more favoured by the patients than the conventional RD and gained similar results in the objective parameters.

The results of this study may contribute to the decision making of the dentists regarding the choice of the isolation system; however, a bigger sample size is still needed to validate the findings presented in this preliminary study. Furthermore, there are more parameters to consider, such as price, operator's preference, colour and thickness of the membranes. The price of the systems OptraDam ${ }^{\circledR}$ Plus and OptiDam $^{\text {TM }}$ is much higher than the price of the conventional RD, which could be another reason for their restricted adoption among dental practitioners. 


\section{Conclusions}

- The placement time of OptiDam ${ }^{\mathrm{TM}}$ was similar to the conventional RD. The placement time of OptraDam ${ }^{\circledR}$ Plus was longer.

- All systems showed comparable high isolation quality.

- The majority of patients declared a higher level of comfort during the treatment with a RD than without it. This opinion was not affected by any of the observed factors.

- The ranking of the isolation systems according to the subjective evaluation by the patients was (from best to worst): OptiDam ${ }^{\mathrm{TM}}$, conventional RD, OptraDam ${ }^{\circledR}$ Plus.

\section{Acknowledgements}

The authors would like to thank Dr. Eva Cermakova from Computer Technology Center, Charles University in Prague, Faculty of Medicine in Hradec Králové, Czech Republic, for help with statistical analysis, and Mr. Parham Yazdani-Fard for the language revision of the article.

The study was financially supported by the programme PRVOUK P37/13.

\section{Conflict of interest disclosure}

Conflicts of interest: none to declare. The authors declare that they are not associated in any way with the companies whose products were used in the study, and that there was no financial or other support from these companies.

\section{References}

1. Glickman GN, Vogt MW. Preparation for treatment. In: Hargreaves KM, Cohen SC, eds. Cohen's Pathways of the Pulp. 10th ed. St. Louis: Mosby, 2011: 88-123.

2. Lin PY, Huang SH, Chang HJ, Chi LY. The effect of rubber dam usage on the survival rate of teeth receiving initial root canal treatment: a nationwide popula- tion-based study. J Endod 2014; 40(11): 1733-7. doi: 10.1016/j.joen.2014.07.007. Epub 2014 Aug 28.

3. Baumann MA, Beer R. Endodontology. 2nd ed. NewYork: Thieme, 2010: 424.

4. Winkler R. Kofferdam in Theorie und Praxis. Berlin: Quintessenz-Verl.-GmbH, 1991: 204.

5. Ahmed HM, Cohen S, Lévy G, Steier L, Bukiet F. Rubber dam application in endodontic practice: an update on critical educational and ethical dilemmas. Aust Dent J 2014; 59(4): 457-63. doi: 10.1111/adj.12210. Epub 2014 Sep 30.

6. Kapitán M. The usage of the rubber dam in restorative dentistry and endodontics (Doctoral thesis). Hradec Králové, Czech Republic: Charles University, 2014.

7. Kapitán M, Šustová Z. The Use of Rubber Dam among Czech Dental Practitioners. Acta Medica (Hradec Králové) 2011; 54(4): 144-8.

8. Ahmad IA. Rubber dam usage for endodontic treatment: A review. Int Endod J 2009; 42(11): 963-72.

9. Anabtawi MF, Gilbert GH, Bauer MR, Reams G, Makhija SK, Benjamin PL, Dale Williams O; National Dental Practice-Based Research Network Collaborative Group. Rubber dam use during root canal treatment: findings from The Dental Practice-Based Research Network. J Am Dent Assoc 2013; 144(2): 179-86.

10. European Society of Endodontology. Quality guidelines for endodontic treatment: consensus report of the European Society of Endodontology. Int Endod J 2006; 39: $921-30$.

11. American Association of Endodontists. AAE position statement: dental dams (released 2010). (Accessed December 12, 2013, at: http://www.aae.org/uploadedfiles /publications_and_research/guidelines_and_position_statements/dentaldamstate ment.pdf).

12. Hill EE, Rubel BS. Do dental educators need to improve their approach to teaching rubber dam use? J Dent Educ 2008; 72(10): 1177-81.

13. Lynch CD, McConnell RJ. Attitudes and use of rubber dam by Irish general dental practitioners. Int Endod J 2007; 40: 427-32.

14. Marshall K. Rubber dam. Br Dent J 1998; 184(5): 218-9.

15. Ryan W, O'Connel A. The attitudes of undergraduate dental students to the use of the rubber dam. J Ir Dent Assoc 2007; 53(2): 87-91.

16. Whitworth JM, Seccombe GV, Shoker K, Steele JG. Use of rubber dam and irrigant selection in UK general dental practice. Int Endod J 2000; 33: 435-41.

17. Filipović J, Jukić S, Miletić I, Pavelić B, Malčić A, Anić I. Patient's attitude to rubber dam use. Acta Stomatol Croat 2004; 38(4): 319-22.

18. Kapitán M, Hodačová L, Jagelská J, Kaplan J, Ivančáková R, Šustová Z. The attitude of Czech dental patients to the use of rubber dam. Health expectations 2013 Jun 24 [Epub ahead of print]. doi: 10.1111/hex.12102.

19. Reuter JE. The isolation of teeth and the protection of the patient during endodontic treatment. Int Endod J 1983; 16: 173-81.

20. Slaus G, Minoodt I, Bottenberg P. The rubber dam, a problem for the dentist or the patient? Rev Belge Med Dent 2005; 60(4): 301-9. [French]

21. Stewardson DA, McHugh ES. Patients' attitudes to rubber dam. Int Endod J 2002; 35(10): 812-9.

22. Kapitán M, Šustová Z, Ivančaková R, Suchánek J. A comparison of different rubber dam systems on a dental simulator. Acta Medica (Hradec Králové) 2014; 57(1): $15-20$.

23. Feierabend SA, Matt J, Klaiber B. A comparison of conventional and new rubber dam systems in dental practice. Oper Dent 2011; 36(3): 243-50.

Received: 05/08/2014

Accepted in revised form: 28/03/2015

\section{Corresponding author:}

Martin Kapitán, Department of Dentistry, Sokolská 581, Hradec Králové 500 05, Czech Republic; e-mail: kapitanm@lfhk .cuni.cz 